LOG \# 281

Radioanalytical Data Quality Objectives and Measurement Quality Objectives during a Federal Radiological Monitoring and Assessment Center Response

E. C. Nielsen

nielsenec@nv.doe.gov

Bechtel Nevada, Remote Sensing Laboratory - Nellis

P.O. Box 98521

Las Vegas, Nevada 89193 


\title{
Radioanalytical Data Quality Objectives and Measurement Quality Objectives during a Federal Radiological Monitoring and Assessment Center Response
}

\author{
E. C. Nielsen
}

Bechtel Nevada

Las Vegas, NV 89193

\begin{abstract}
During the early and intermediate phases of a nuclear or radiological incident, the Federal Radiological Monitoring and Assessment Center (FRMAC) collects environmental samples that are analyzed by organizations with radioanalytical capability. Resources dedicated to quality assurance (QA) activities must be sufficient to assure that appropriate radioanalytical measurement quality objectives (MQOs) and assessment data quality objectives (DQOs) are met. As the emergency stabilizes, QA activities will evolve commensurate with the need to reach appropriate DQOs. The MQOs represent a compromise between precise analytical determinations and the timeliness necessary for emergency response activities. Minimum detectable concentration (MDC), lower limit of detection, and critical level tests can all serve as measurements reflecting the MQOs. The relationship among protective action guides (PAGs), derived response levels (DRLS), and laboratory detection limits is described. The rationale used to determine the appropriate laboratory detection limit is described.
\end{abstract}




\section{Introduction}

The initial federal response for a nuclear/radiological incident is from the U.S. Department of Energy's (DOE) regionally-based Radiological Assistance Program (RAP), Emergency Management Teams, and Nuclear Incident Response Team Assets. These teams communicate incident information to the Lawrence Livermore National Laboratory National Atmospheric Release Advisory Center (NARAC) and the Sandia National Laboratories High Consequence Assessment and Technology Department. These organizations have tools that are used to characterize the airborne source material and simulate atmospheric dispersion and surface deposition. Deposition and dispersion models are needed to predict dose to humans from airborne or ground contamination through several pathways (air immersion exposure, ground exposure, inhalation, and ingestion). Modeling results are typically plotted as maps of areas corresponding to a range of air or ground contamination levels that might be encountered by field monitoring teams, and for areas where the predicted (modeled) dose exceeds PAGs.

As appropriate, the DOE's Aerial Measuring System (AMS), which is an aerial radiological surveillance capability, is deployed. The AMS uses two platforms: a fixed-wing aircraft for rapid response to measure areas of relatively high concentrations of higher energy gamma-emitting radionuclides, and a helicopter for higher spatial resolution of lower concentrations with the capability of detecting lower-energy gamma emitters. The AMS fixed-wing aircraft objective is to provide decision makers with an overview of the radiological 
impact as quickly as possible. The data from the AMS aircraft are usually the first comprehensive set of measurements and are used by the modelers to normalize and refine their predictions and by decision makers for response actions. The AMS data may cover the area from several kilometers upwind of the release location to the farthest downwind extent of the deposition. The width of the area flown will depend on the modeled deposition pattern.

Modeling can help identify the most likely areas of concern for the responders. However, it is vitally important that aerial surveys and ground-truth measurements be taken as soon as practical after the event to allow the refinement of such models and to start the development of data maps that truly identify the hazards and issues as they are in the field. The primary goal is to replace the early model-based predictions, used to project initial protective actions, with actual monitoring results.

Initial monitoring activities will focus on protecting the public and responders. One of the first sampling priorities is establishing a defendable resuspension factor. This will require collecting air particulate samples; conducting alpha, beta, and gamma radiation surveys; and performing an in situ gamma spectrum collection and analysis. A soil sample is also collected at this site for later analysis to further quantify resuspension levels. Field teams are also equipped with tools for a variety of sampling activities to allow them to collect multiple environmental samples such as soil, water, milk, vegetation, foliage, etc., for definitive radioanalyses to confirm the initial field measurements. 
Instrument surveys are conducted when a sample is collected. These surveys will help determine the presence or absence of a plume and field radiation levels.

During the early phase, there is little capacity for analytical radiochemistry and decisions will be made based on predictive dispersion models supplemented with field radiation measurements. The analytical response during this phase will be limited to field instrumentation, mobile laboratories, and local analytical capability. A database of radioanalytical organizations' capability, capacity, and competence indicators (Radioanalytical Organization Database for Emergency Operations - [RODEO]) is available to the FRMAC laboratory supervisor. During the initial phase of the incident, the quantity of analytical data needed for assessment quickly increases. The DQOs are adjusted to be commensurate with the urgency of the decision at hand and the risk of potential consequences from an incorrect decision.

Assessment commences as soon as information begins to arrive. The focus is on performing assessments that will provide guidance for decision makers regarding what areas may warrant evacuation and/or whether citizens can be sheltered-in-place to avoid doses greater than the PAGs. Initial predictions and projections will be made using available knowledge and experience to determine early bounding assumptions. The initial NARAC model will provide a prediction of what areas are most affected and where to begin sheltering, evacuation, and initial data-gathering efforts.

As more field data becomes available, including the AMS flyover data, the amount of radioactive material released can reasonably be estimated. The 
modeled plume is then fitted to field measurements to provide the first reasonable view of the overall extent of the impacted areas so that accurate assessments of the expected radiation dose can be made. This information is plotted on a map showing areas where the potential dose may exceed the PAG without implementation of protective actions. As more data becomes available, the plume model inputs are further refined to adjust the plume model to properly match the results being observed in the field.

The next important action for the assessment scientist is to determine the relative concentrations and identification of the radionuclides released. This source term information is very important because it has significant impact on the dose assessment calculations. Different methods can be used to obtain this information depending upon the type of release. For a nuclear weapon accident, nuclear detonation, or nuclear reactor release, the expected radionuclide mixture can reasonably be determined from process knowledge based on the material released. However, for a radiological dispersal device (RDD), it is much more difficult to determine the radionuclides involved and their relative abundance. If there is any intelligence information related to the release, that information can also be used. However, until appropriate laboratory analysis is performed, the assessment scientists cannot be sure of the identity of all of the radionuclides involved in an RDD event.

Early in the event, all information available, as well as the experience of personnel, will be used to make initial predictions. As more data becomes available, this prediction will be advanced, allowing refinement of plume 
predictions, which ultimately bounds the predicted areas where PAGs may be exceeded. During this phase, geographical information system (GIS) maps can be created and reproduced every few hours. Changes to the plume model can occur with each iteration as better and more precise measurement information becomes available.

As initial samples are submitted to radioanalytical laboratories, the nuclides of interest and MQOs must be communicated to laboratory personnel.

\section{DQOs for Assessment}

In addition to the response structure, the federal government, through the Environmental Protection Agency (EPA) and the U.S. Food and Drug Administration (FDA), has established PAGs for the public and the environment. These PAGs were published in the EPA Manual of Protective Action Guides and Protective Actions for Nuclear Incidents (EPA, 1992). This document divides the response to a nuclear incident into three phases, each with its own set of PAGs. These are termed the early, intermediate, and late phases. These phases cannot be represented by specific time periods since events vary greatly in magnitude and phases may overlap due to the transition of activities. These guidelines are used by the FRMAC in developing data products and by the Advisory Team in providing protective action recommendations to state and local decision makers (Table 1). It is important to note that any support provided by the federal government in these areas is at the request of state and local authorities. 
A derived response level (DRL) is the quantity of a surrogate or radionuclide at which a particular PAG will be exceeded under selected assumptions. Numerous DRLs are required, each corresponding to a particular surrogate/nuclide, PAG, and set of assumptions. DRLs may require revision to reflect radioactive decay or modification of assumptions. DRLs are subject to a "sum of the fractions" rule. This is where the dose calculated from each radionuclide measured or modeled is summed such that the total dose from all the radionuclides is calculated and compared to the PAG. Since each radionuclide has a different dose conversion factor for each pathway, the most prevalent radionuclide may not be the one that is causing the largest fraction of the projected dose.

The FDA recommended a limited set of standards for the presence of radioactivity in human food (FDA, 1998). These recommendations are known as the derived intervention level (DIL) for specific radionuclides and groups of radionuclides (Table 2). A DIL corresponds to the radioactive concentration in food present during the relevant period of time that, in the absence of any intervention, could lead to an individual receiving a radiation dose equal to the PAG. The FDA DILs provide a large margin of safety for the public because each is based on the most vulnerable portion of the population. In addition, protective actions would be taken if the radionuclide concentrations were to reach the DIL at any point in time, though these concentrations would need to be sustained throughout the extended time period for the dose to actually reach the PAG. DILs are based on the total food in the diet and assume that contaminated 
food could comprise $30 \%$ of the total diet. This was based on the expectation that contaminated food would not exceed $10 \%$ of the total diet and included a three-fold safety factor to account for limited sub-populations that might be more dependent on local food supplies.

Because of differences in assumptions (more conservative), the FDA DILs do not utilize the "sum of the fractions" rule as PAGs do. Instead, each DIL is like a "stand-alone" DRL and can be independently used for detection limit determination.

The EPA is currently considering a new PAG for drinking water. This new PAG would limit the dose from consumption of one liter of water per day to 500 mrem during the first year. It is anticipated that current drinking water standards (4 mrem/year) will apply after the first year. It is not clear whether this dose standard is in addition to the existing PAG or a pathway standard within the current PAG. This guidance could be published in 2006. Current PAGs are summarized in Table 1.

\section{Derivation of Laboratory Measurement Quality Objectives}

Assessment DAQs (derived from PAGs and DILs) drive the needs for analytical MQOs. When the source term of the release is known or can be estimated with a quantifiable level of confidence, analytical MQOs are a rather straightforward calculation. Marker radionuclides (that can be easily quantified with field instruments) are identified and the dose contributions of additional radionuclides are scaled to calculate a total dose. Detection limit requirements 
for each radionuclide can then be communicated to laboratories supporting the response effort.

An example of this situation would be a scenario involving a nuclear power plant or a spent fuel incident. In cases like this where the source term is well defined and the material is homogenous, scaling radionuclides will reduce much of the immediate need for radioanalytical information. Proportional DRLs can be calculated for each radionuclide and these, in turn, are used as the basis for determining laboratory detection limit requirements.

In other scenarios, where the source term is unknown, there is a great deal of uncertainty in trying to determine appropriate radionuclides to analyze. Additionally, the method to determine the appropriate detection limits needed to identify areas where PAGs may be exceeded is unknown. Using situational awareness, experience, and best-guess estimates to determine which radionuclides to analyze for and recommending detection limits to laboratories, is not a reproducible process among individuals, and could result in significant uncertainties in determining the areas where PAGs may be exceeded.

Documenting a process to use in these cases will enable the estimation of uncertainty and bias of these cases.

\section{MQO Process}

DRLs are published in Volume II of the FRMAC Assessment Manual (DOE, 2003b). They are calculated for a variety of exposure scenarios using the dose conversion factors from Federal Guidance Report No. 11 (EPA, 1988). 
When radionuclides are sorted in ascending order of their $\mathrm{DRL}$, the radionuclide with the highest dose conversion factor is at the top of the table. The top entry is the radionuclide that, if present, will produce the highest dose for a given concentration in the pathway or model selected. An example for early phase deposition is found in Table 3. In this case, the pathway and model incorporates the direct dose from groundshine, and the inhalation doses from resuspension. Other models and assumptions will produce different values, but are primarily driven by the dose-conversion factor utilized. Only the isotopes with the highest dose-conversion factors (and, thus, low DRLs) are listed in this table. Virtually all other radionuclides will be of less concern from a detection limit criteria.

\section{Sum of the Fractions Rule}

Because PAGs are a total projected dose and DRLs are calculated on the basis of a single radionuclide producing a dose equal to the PAG, if there are multiple radionuclides present, a calculation must be applied to modify each DRL to a level where the dose from the mixture will not exceed the PAG. This calculation is commonly referred to as the "sum of the fractions rule" or the "unity rule."

Mathematically, this can be described as the sum of the activity concentration for each measured radionuclide divided by its DRL. Table 3 indicates the DRL for Pu-239 is $34 \mathrm{uCi} / \mathrm{m}^{2}$. A soil sample collected by the FRMAC soil sample template is approximately 360 grams (based on a collection area of $10 \mathrm{~cm} \times 10 \mathrm{~cm}\left(100 \mathrm{~cm}^{2} \times 2 \mathrm{~cm}\right.$ [deep] $\left.\times 1.8 \mathrm{~g} / \mathrm{cc}\right)$ that will typically 
produce a nominal laboratory value of $944 \mathrm{pCi} / \mathrm{g}$. If the actual Pu-239 concentration reported by the laboratory was $100 \mathrm{pCi} / \mathrm{g}$, the Pu-239 would "use up" approximately $11 \%$ of the PAG. If Am-241 were the other radionuclide present, a concentration greater than $89 \%$ of the table value $(816 \mathrm{pCi} / \mathrm{g})$ would produce a total greater than $100 \%$ of the PAG.

This same calculation must be applied to detection limit requirements communicated to analytical laboratories. The possibility of a high dose conversion factor radionuclide "hiding" in a mixture must be considered when determining MQOs for each sample.

Consider modifying the previous example to include Cs-137. The DRL for Cs-137 converts to a nominal soil sample concentration of $55,600 \mathrm{pCi} / \mathrm{g}$. If there were Cs-137 present at approximately $50 \%$ of this $\mathrm{DRL}(27,600 \mathrm{pCi} / \mathrm{g})$, this would then force the detection limit for the Am-241 down to $50 \%$ of the soil concentration listed or $417 \mathrm{pCi} / \mathrm{g}$. The situation could be complicated further by the presence of Pu-239 at even a smaller fraction of its limit (10\%). Thus, $94 \mathrm{Ci} / \mathrm{g}$ of Pu-239 added to this mixture would indicate that occupation of this area beyond 4 days (100 hours) would exceed the PAG.

\section{Current and Future Work}

With an obviously unknowable situation during an emergency, it is difficult to determine what to tell laboratories to look for and to what detection limits. FRMAC is developing an automated tool that will assist the assessment scientist and laboratory analysis supervisor in answering these questions. 
At its heart, the procedure iteratively calculates a DRL for each radionuclide based on each piece of information as it becomes available. As in situ gamma spectroscopy results become available, they are fed into the algorithm and the DRLs for all of the other radionuclides are recalculated. As additional information is added, the table is reshuffled to order the radionuclides in ascending order of their DRL. This process has been demonstrated on a small scale with Microsoft Excel spreadsheets.

There are limitations and uncertainties inherent to this methodology that have yet to be fully quantified. Inhomogeneity in deposition of the radionuclide mixture is a large source of uncertainty. This inhomogeneity could be caused by the chemical and physical forms of the dispersed material as well as spatial and temporal variations of the dispersal combined with micrometeorology. Full implementation of this solution will not prevent analytical errors from being made during an emergency, but will prevent an error from becoming a catastrophe.

\section{Acknowledgement}

This manuscript has been authored by Bechtel Nevada under Contract No. DE-AC08-96NV11718 with the U.S. Department of Energy. The United States Government retains and the publisher, by accepting the article for publication, acknowledges that the United States Government retains a nonexclusive, paid-up, irrevocable, world-wide license to publish or reproduce the published form of this manuscript, or allow others to do so, for United States Government purposes. 


\section{References}

DHS, 2004: National Response Plan, December 2004, Department of Homeland Security, Washington, DC

DOE, 1993: Radiation Protection of the Public and Environment w/change 2, U.S. Department of Energy Order 5400.5

DOE, 2003a: FRMAC ASSESSMENT MANUAL - METHODS - VOLUME 1 (The Federal Manual for Assessing Environmental Data During a Radiological Emergency), April 2003, SAND2003-1071P, Albuquerque, NM, 87185

DOE, 2003b: FRMAC ASSESSMENT MANUAL - TABLES, CHARTS, WORKSHEETS, GLOSSARY, REFERENCES - VOLUME 2 (The Federal Manual for Assessing Environmental Data During a Radiological Emergency), April 2003, SAND2003-1072P, Albuquerque, NM, 87185

DOE, 2003c: FRMAC ASSESSMENT MANUAL - PRE-ASSESSED DEFAULT SCENARIOS - VOLUME 3 (The Federal Manual for Assessing Environmental Data During a Radiological Emergency), April 2003, SAND2003-1073P, Albuquerque, NM, 87185

EPA, 1988: Limiting Values of Radionuclide Intake and Air Concentration and Dose Conversion Factors for Inhalation, Submersion, and Ingestion, Federal Guidance Report No. 11, EPA-520/1-88-020, 1988

EPA, 1992: Manual of Protective Action Guides and Protective Actions for Nuclear Incidents (EPA 400-92-001), Office of Radiation Programs, U.S. Environmental Protection Agency, Washington, DC 20460 
EPA, 1993: External Exposure to Radionuclides in Air, Water, and Soil, Federal Guidance Report No. 12, EPA-402/R-93-081, 1993

EPA, 2000: Multi-Agency Radiation Survey and Site Investigation Manual (MARSSIM), EPA 402-R-97-016 Rev 1, August 2000, Washington, DC 20460

FDA, 1998: Accidental Radioactive Contamination of Human Food and Animal Feeds: Recommendations for State and Local Agencies, August 1998, U.S. Food and Drug Administration, Rockville, MD 20850

Nasstrom, John S., et al., 2006: The National Atmospheric Release Advisory Center (NARAC) Modeling and Decision Support System for Radiological and Nuclear Emergency Preparedness and Response, Int. J. of Risk Assessment and Management. In Press

NRC, 1974: Termination of Licenses for Nuclear Reactors, U.S. Nuclear Regulatory Commission Regulatory Guide 1.86

NRC, 1980: Criteria for Preparation and Evaluation of Radiological Emergency Response Plans and Preparedness in Support of Nuclear Power Plants (NUREG-0654, FEMA-REP-1, Rev. 1 Addenda), U.S. Nuclear Regulatory Commission. Washington, DC 20555

NRC, 2004: Multi-Agency Radiological Laboratory Analytical Protocols Manual (MARLAP), NUREG-1576, EPA 402-B-04-001A, NTIS PB2004-105421. July 2004 
Table 1. Protective Action Guidelines (EPA)

\begin{tabular}{|l|l|l|}
\hline \multicolumn{3}{|c|}{ Protective Action Guidelines (EPA) } \\
\hline Timeframe & $\begin{array}{l}\text { Projected } \\
\text { Dose }\end{array}$ & Notes \\
\hline 1-4 Days & 1-5 rem & Evacuation or sheltering \\
\hline $\begin{array}{l}\text { 1st Year } \\
\text { 2nd Year and any } \\
\text { single year after first }\end{array}$ & 2 rem & Relocation \\
\hline 50 year total & 5 rem & Relocation \\
\hline 1st Year & 500 mrem & $\begin{array}{l}\text { Includes any dose received } \\
\text { during first and second year }\end{array}$ \\
\hline & Ingestion PAG (FDA) \\
\hline Timeframe & $\begin{array}{l}\text { Projected } \\
\text { Dose }\end{array}$ & Notes \\
\hline 1 year & 500 mrem & Commited dose to age 70 \\
\hline 1 year & 5 rem & $\begin{array}{l}\text { Dose to individual tissue or } \\
\text { organ }\end{array}$ \\
\hline
\end{tabular}

Table 2. Derived Intervention Levels

\begin{tabular}{|c|c|}
\hline \multicolumn{2}{|c|}{ FDA DIL } \\
\hline Radionuclide Group & pCi/kg \\
\hline${ }^{238} \mathrm{Pu}+{ }^{239} \mathrm{Pu}+{ }^{241} \mathrm{Am}$ & $5.40 \mathrm{E}+01$ \\
\hline${ }^{90} \mathrm{Sr}$ & $4.30 \mathrm{E}+03$ \\
\hline${ }^{131} \mid$ & $4.60 \mathrm{E}+03$ \\
\hline${ }^{134} \mathrm{Cs}+{ }^{137} \mathrm{Cs}$ & $3.20 \mathrm{E}+04$ \\
\hline${ }^{103} \mathrm{Ru}+{ }^{106} \mathrm{Ru}$ & $\begin{array}{l}\left({ }^{103} \mathrm{Ru} / 180,000\right)+ \\
\left({ }^{106} \mathrm{Ru} / 12,000\right)<1\end{array}$ \\
\hline
\end{tabular}


Table 3. Early Phase Derived Response Levels

\begin{tabular}{|c|c|c|c|c|c|}
\hline Radionuclide & $\begin{array}{c}\text { Early Phase } \\
\text { Deposition \& } \\
\text { Resuspension } \\
\text { Inhalation }\left(\mathrm{uCi} / \mathrm{m}^{2}\right) \\
\end{array}$ & $\begin{array}{l}\text { Nominal } \\
\text { pCi/g soil }\end{array}$ & Radionuclide & $\begin{array}{l}\text { Early Phase } \\
\text { Deposition \& } \\
\text { Resuspension } \\
\text { Inhalation }\left(\mathrm{uCi} / \mathrm{m}^{2}\right)\end{array}$ & $\begin{array}{l}\text { Nominal } \\
\text { pCi/g soil }\end{array}$ \\
\hline${ }^{227} \mathrm{Ac}$ & $2.20 \mathrm{E}+00$ & $6.11 E+01$ & ${ }^{230} \mathrm{Th}$ & $4.50 E+01$ & $1.25 \mathrm{E}+03$ \\
\hline${ }^{232} \mathrm{Th}$ & $8.90 \mathrm{E}+00$ & $2.47 E+02$ & ${ }^{243} \mathrm{Cm}$ & $4.70 E+01$ & $1.31 E+03$ \\
\hline${ }^{231} \mathrm{~Pa}$ & $1.10 \mathrm{E}+01$ & $3.06 E+02$ & ${ }^{244} \mathrm{Cm}$ & $5.90 E+01$ & $1.64 \mathrm{E}+03$ \\
\hline${ }^{232} U$ & $2.20 \mathrm{E}+01$ & $6.11 E+02$ & ${ }^{252} \mathrm{Cf}$ & $9.30 E+01$ & $2.58 E+03$ \\
\hline${ }^{237} \mathrm{~Np}$ & $2.70 E+01$ & $7.50 \mathrm{E}+02$ & ${ }^{236} \mathrm{Pu}$ & $1.00 E+02$ & $2.78 E+03$ \\
\hline${ }^{245} \mathrm{Cm}$ & $3.20 E+01$ & $8.89 E+02$ & $\begin{array}{l}{ }^{233} \mathrm{U},{ }^{234} \mathrm{U}, \mathrm{U} \\
\text { Enrich }\end{array}$ & $1.10 E+02$ & $3.06 \mathrm{E}+03$ \\
\hline${ }^{241} \mathrm{Am},{ }^{243} \mathrm{Am}$ & $3.30 \mathrm{E}+01$ & $9.17 E+02$ & $\begin{array}{l}{ }^{235} \cup,{ }^{236} \cup,{ }^{238} U, U \\
\text { Dep, U Nat }\end{array}$ & $1.20 E+02$ & $3.33 E+03$ \\
\hline $\begin{array}{l}{ }^{239} \mathrm{Pu},{ }^{240} \mathrm{Pu}, \\
{ }^{242 \mathrm{~m}} \mathrm{Am}\end{array}$ & $3.40 \mathrm{E}+01$ & $9.44 \mathrm{E}+02$ & ${ }^{147} \mathrm{Sm}$ & $2.00 E+02$ & $5.56 \mathrm{E}+03$ \\
\hline${ }^{242} \mathrm{Pu}$ & $3.60 \mathrm{E}+01$ & $1.00 E+03$ & \multirow{3}{*}{\multicolumn{3}{|c|}{$\begin{array}{l}\text { The Early Phase deposition DRL expresses the Early } \\
\text { Phase PAG in terms of the level of deposition on the } \\
\text { ground that corresponds to a projected dose equal to } \\
\text { the PAG. }\end{array}$}} \\
\hline${ }^{238} \mathrm{Pu}$ & $3.70 E+01$ & $1.03 E+03$ & & & \\
\hline${ }^{228} \mathrm{Th}$ & $4.30 \mathrm{E}+01$ & $1.19 E+03$ & & & \\
\hline
\end{tabular}

